
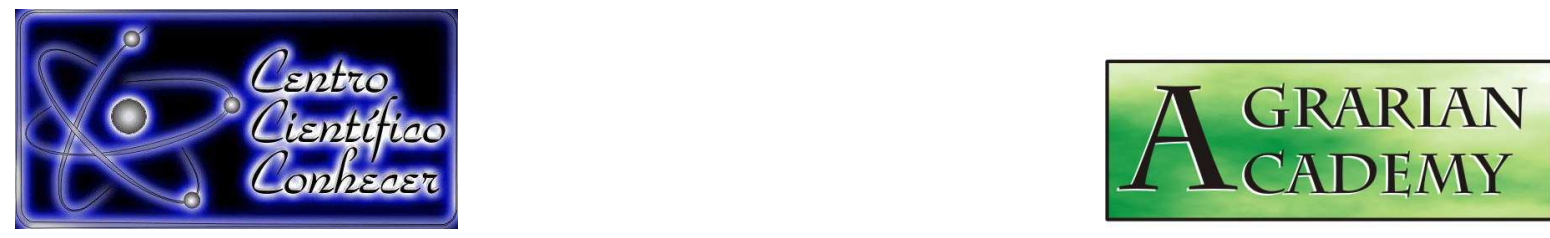

\title{
ANÁLISE DA ESTRUTURA E DIVERSIDADE DO COMPONENTE ARBOREO- ARBUSTIVO DE FRAGMENTO VEGETACIONAL DO CERRADO, MARANHÃO BRASIL
}

\author{
Antônio Edmilson Camelo Júnior ${ }^{1}$, Gustavo da Silva Gomes ${ }^{1}$, Claudeson de Oliveira \\ Velozo $^{1}$, Guilherme Sousa da Silva ${ }^{2}$, Gonçalo Mendes da Conceição ${ }^{3}$ \\ 1 Acadêmico do Curso de Ciências Biológicas Licenciatura, da Universidade \\ Estadual do Maranhão, Caxias-MA, Brasil (antonioedmilsom@hotmail.com) \\ 2 Mestrando do Programa de Pós-graduação em Botânica do Instituto Nacional de \\ Pesquisas da Amazônia-INPA, Manaus-AM, Brasil \\ 3 Professor Dr. do Centro de Estudos Superiores de Caxias/CESC, da Universidade \\ Estadual do Maranhão/UEMA, Maranhão/Brasil; Programa de Pós-Graduação em \\ Biodiversidade, Ambiente e Saúde/PPGBAS, Caxias-MA, Brasil
}

Recebido em: 30/11/2017 - Aprovado em: 15/12/2017 - Publicado em: 31/12/2017 DOI: 10.18677/Agrarian Academy 2017b5

\begin{abstract}
RESUMO
O trabalho teve como objetivo caracterizar a estrutura e diversidade do componente arbóreo-arbustivo da Área de Proteção Ambiental do Buriti do Meio, um fragmento vegetacional de cerrado com considerável riqueza de espécies, no Leste do estado do Maranhão. Para a caracterização do estrato arbóreo-arbustivo, foi utilizado de levantamento florístico através do método de parcelas. Os espécimes foram coletados, herborizados e identificados, sendo elaboradas análises dos parâmetros estruturais da vegetação para as espécies e parcelas mensuradas, a partir de medidas como densidade, diâmetro e área basal das espécies. Para análise de diversidade vegetacional foram usados índices para estimar diversidade máxima, riqueza, dominância, equitabilidade e composição da vegetação, sendo gerenciados pelo software Mata Nativa 3. Analisou-se 101 espécimes, distribuídos em 31 espécies. O principal hábito de vida das espécies é árvore. Tratando das análises estruturais da vegetação por espécie e parcela, as populações de Pseudobombax marginatum foram determinantes para indicar os maiores valores de densidade absoluta e relativa, e os valores de área basal e DNS foram variáveis de acordo com as espécies e parcelas. As análises de diversidade da vegetação através dos índices calculados corroboraram com vários trabalhos em riqueza local, apresentando um padrão para o estrato arbóreo-arbustivo do cerrado no Leste maranhense.
\end{abstract}

PALAVRAS-CHAVE: Análise da vegetação, Composição florística, Fitossociologia 


\title{
ANALYSIS OF STRUCTURE AND DIVERSITY OF THE TREE-ARBUSTIVE COMPONENT OF CERVADO VEGETACIONAL FRAGMENT, MARANHÃO, BRAZIL
}

\begin{abstract}
The objective of this work is to characterize the structure and diversity of the arboreal-shrub component of the Buriti do Meio Environmental Protection Area, a vegetative fragment of cerrado with considerable species richness, in the eastern state of Maranhão. For the characterization of the arboreal-shrub stratum, floristic survey was carried out using the Parcelas method, with inclusion criterion of the species. The specimens were collected, herborized and identified, and analyzes of structural parameters of the vegetation were performed for the species and plots measured, based on measures such as density, diameter and basal area of the species. For vegetation diversity analysis, several ecological indices were estimated to estimate maximum diversity, richness, dominance, equitability and vegetation composition, being managed by the Mata Nativa 3 software. A total of 101 specimens distributed in 31 species were analyzed. The main habit of species life is tree. Treating the structural analysis of vegetation by species and plot, the populations of Pseudobombax marginatum were determinant to indicate the highest values of absolute and relative density, and the values of basal area and DNS were variable according to the species and plots. The analysis of vegetation diversity through the calculated indices corroborated with several work on local richness, presenting a pattern for the arboreal-shrub stratum of the cerrado in eastern Maranhão.
\end{abstract}

KEYWORDS: Vegetation analysis, Flower composition, Phytosociology

\section{INTRODUÇÃO}

Entender a florística e a organização comunitária da vegetação natural têm um grande valor significativo, tanto para 0 avanço de modelos de conservação e manejo de áreas remanescentes, como para o restabelecimento de áreas perturbadas ou degradadas (SALIS et al.,1994). Ao lado do grande potencial de aplicação, levantamentos da composição florística e da estrutura comunitária da vegetação natural são de fundamental importância para o desenvolvimento da teoria ecológica e fitogeográfica, pois além de gerarem informações cruciais sobre a distribuição geográfica das espécies, permitem que se amplie o conhecimento sobre a abundância dos organismos em diferentes locais, fornecendo bases consistentes para a criação de Unidades de Conservação (GOMES, 2004).

Com o tempo, surgiu a necessidade de informações quantitativas sobre a estrutura de cada tipo de vegetação da terra para permitir comparações de melhor qualidade. Nesse contexto foi que se desenvolveu a fitossociologia, que é o estudo das causas e efeitos da coabitação de plantas em dado ambiente, do surgimento, constituição e estrutura dos agrupamentos vegetais e dos processos que implicam na continuidade ou na mudança ao longo do tempo (MARTINS, 2003).

Dentre os vários domínios fitogeográficos brasileiros o cerrado é considerado um dos pontos quentes (hot spots) para a conservação da biodiversidade no mundo (MYERS et al., 2000). É reconhecido biologicamente, como um domínio fitogeográfico de maior riqueza florística do mundo, com cerca de 11.000 espécies de vegetais nativos (RATTER et al., 2003; FIASCHI; PIRANI, 2009). 
Possui área com 2,4 milhões de quilômetros quadrados, o que equivale a aproximadamente $22 \%$ do território nacional, sendo o segundo maior domínio fitogeográfico brasileiro, somente superado pela Amazônia (SANO; FERREIRA, 2005; SANO et al., 2008).

O Cerrado é um constituinte fundamental do ambiente fitogeográfico e predominante no estado do Maranhão, possuindo vários representantes endêmicos, mas a exploração da região tem conduzido à fragmentação das paisagens naturais, perdendo cerca de 88 Mha (46\%) da cobertura vegetal nativa, restando apenas $19,8 \%$ inalterado, sendo que entre 2002 e 2011, as taxas de desmatamento no Cerrado ( $1 \%$ ao ano) foram 2,5 vezes mais altas do que na Amazônia, podendo ser extinto em cerca de 30 anos (STRASSBURG et al., 2017).

Vários são os estudos relacionados a Florística e Fitossociologia sobre Cerrado principalmente no estado do Maranhão, destacando-se os trabalhos de Conceição e Castro (2009), no Parque Estadual do Mirador; Soares (1996) sobre Florística e Fitossociologia em uma área de Imperatriz; Ferreira (1997) sobre fitossociologia de uma área em Afonso Cunha; Soares et al. (2010) com Florística e Fitossociologia de uma área no Sudoeste do Maranhão, e apenas três trabalhos direcionados ao Leste do Maranhão: Neres e Conceição (2010); Silva-Filho (2006) ambos com trabalho de Florística e Fitossociologia da Área de Proteção Ambiental Municipal do Inhamum em Caxias/MA e Teixeira-junior e Conceição (2001) em trabalho de Fitossociologia de um fragmento no município de Caxias.

Com a perspectiva de aumentar o nível de conhecimento sobre a vegetação do Maranhão, a Área de Proteção Ambiental Municipal do Buriti do Meio, é uma área de cerrado com considerável mosaico de fisionomias que apresenta os primeiros estudos florísticos para o conhecimento da composição vegetal e que merece atenção pelas ações antrópicas efetuadas. Dessa forma o trabalho teve como objetivo caracterizar a estrutura e diversidade do componente arbóreo-arbustivo da APA, um fragmento vegetacional de cerrado com considerável riqueza de espécies no Leste maranhense.

\section{MATERIAL E MÉTODOS}

O estado do Maranhão possui área superficial de $331.983,29 \mathrm{~km} 2$, sendo 0 oitavo maior Estado brasileiro e o segundo do Nordeste em extensão territorial (IBGE, 2002). Está localizado entre os paralelos $1^{\circ} 01^{\prime}$ e $10^{\circ} 21^{\prime}$ Sul e os meridianos 41ㄴㅇ' e 4850' Oeste. O Estado possui cinco Mesorregiões Geográficas, onde estão inseridos os 217 municípios (ESTADO DO MARANHÃO, 2011). A região Leste é uma das maiores com o clima do tipo subúmido seco, com temperatura média anual de $26^{\circ} \mathrm{C}$ e $27^{\circ} \mathrm{C}$, umidade relativa do ar entre $70 \%$ a $73 \%$ e precipitação pluviométrica entre 1600 a $2000 \mathrm{~mm}$, apresentando como principal cobertura vegetal o Cerrado, com várias fisionomias (MONTES et al., 1997).

A Área de Proteção Ambiental Municipal do Buriti do Meio foi criada pela Lei no 1.540/2004 de 25 de março de 2004, localizada no Projeto de Assentamento do Buriti do Meio e Santa Rosa, no $2^{\circ}$ Distrito, afastada a $35 \mathrm{~km}$ do perímetro urbano da

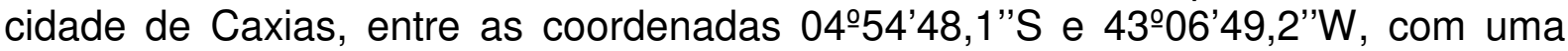
área de 58.347, 30 ha. (Fig. 1). A vegetação da área de estudo é constituída por diferentes fisionomias de cerrado natural e antropizados, com solos arenosos, ácidos, pobres em nutrientes e frágeis (IBGE, 2010). 


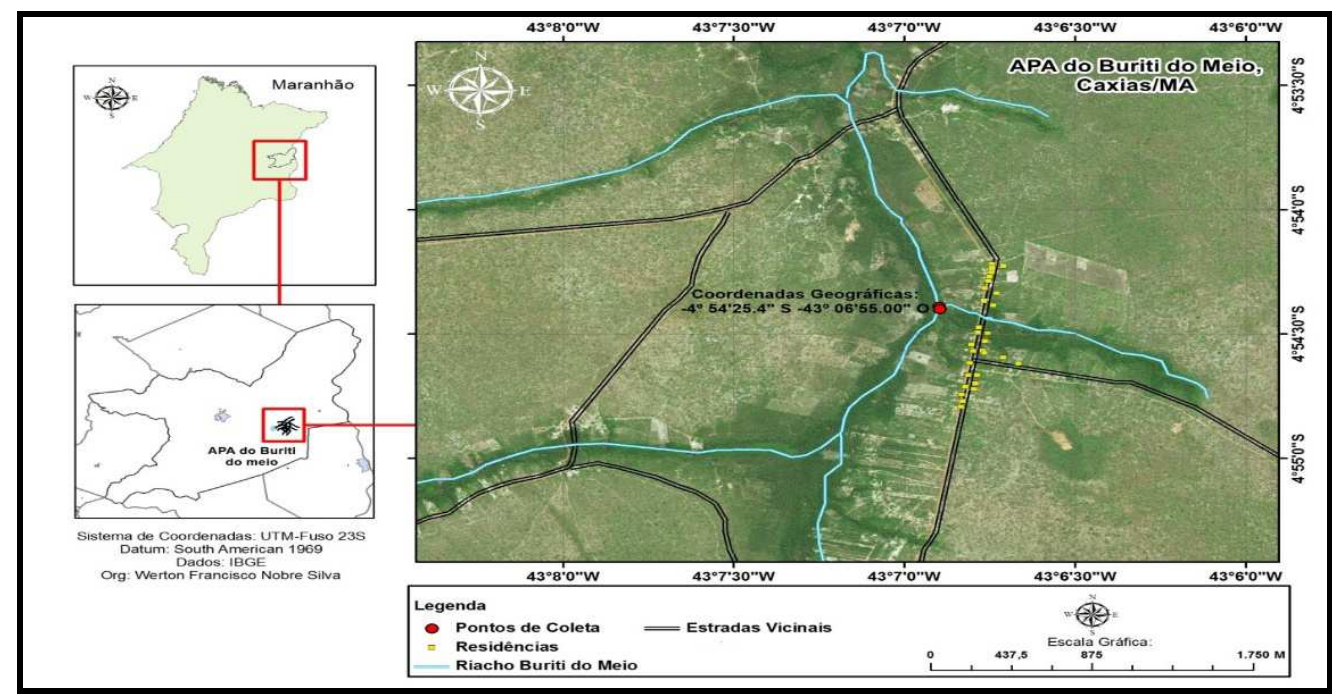

FIGURA 1. Mapa da Área de Proteção Ambiental do Buriti do Meio.

Fonte: Organização: SILVA (2016).

Para a caracterização do estrato arbóreo-arbustivo, foi utilizado um levantamento florístico através do método de Parcelas, de tamanho $10 \times 10 \mathrm{~m}$, onde foram incluídos na amostragem todos os indivíduos lenhosos (arbustos, arbóreos) com diâmetro do caule ao nível do solo (DNS) igual ou maior que $3 \mathrm{~cm}$. Foram definidas sete parcelas para estudo da vegetação da área (quatro do lado direito da estrada vicinal e três do lado esquerdo) sendo delimitadas de acordo com a abundância vegetal de cada ponto de coleta e distante uma da outra cerca de 10 metros. Foram coletados todos os espécimes de cada parcela através do critério de inclusão delimitado, utilizando metodologia preconizada por Fidalgo e Bononi (1989) para coleta das amostras, sendo que o critério de inclusão com DNS igual ou maior que $3 \mathrm{~cm}$, permitirá possíveis comparações, uma vez que o mesmo garante um recrutamento de uma riqueza maior de espécies. Todo o material, coletado das parcelas, foi herborizado e identificado ao nível específico, sendo incorporados as exsicatas ao Herbário Professor Aluízio Bittencourt, do Centro de Estudos Superiores de Caxias CESC/UEMA.

De cada indivíduo amostrado, foram tomados os seguintes dados e anotados em caderno de campo, para organização e controle das espécies: Forma de vida (Fv), Número da parcela (Np), Número do indivíduo na parcela (Ni), Diâmetro do caule ao nível do solo (DNS), Altura do caule (Ac), Altura total (At), Número da coleta (Nc), Nome vulgar da espécie (Nv).

Com a aquisição dos dados foram feitas análises dos parâmetros estruturais da vegetação para as espécies e parcelas mensuradas, elencando-se para análise das espécies o número de indivíduos por espécie, Densidade Absoluta e Relativa, bem como a média e o valor máximo e mínimo do Diâmetro a Nível do Solo (DNS). Para análise das parcelas foram categorizados o número de indivíduos por parcela, Área basal e média, valor máximo e mínimo do Diâmetro a Nível do Solo (DNS). Os dados foram mensurados através do software Mata Nativa 3, para organização e resolução amostral eficiente.

Para análise de diversidade vegetacional além de verificar o número de indivíduos e espécies por parcela, foram mensurados os seguintes índices: Diversidade Máxima - $\ln (S)$; Diversidade de Shannon-Weaver - H'; Dominância de 
Simpson - C; Equitabilidade de Pielou - J e Coeficiente de Mistura de Jentsch - QM, índices que servirão para estimar a riqueza local, a relação de espécies abundantes e raras, dominância de espécies, uniformidade da distribuição das espécies na amostra e a composição florística da vegetação analisada respectivamente. Todos os índices também foram gerenciados através do software Mata Nativa 3.

\section{RESULTADOS E DISCUSSÃO}

Quanto aos aspectos florísticos da área, foram analisados 101 espécimes distribuídos em 31 gêneros e 31 espécies, que se agruparam nos padrões metodológicos das sete parcelas inventariadas. Quanto ao hábito de crescimento o predominante foi o tipo árvore com 55 indivíduos, seguido por arbusto com 38 indivíduos e subarbustivo com apenas oito indivíduos (Figura 2). O cerrado sensu stricto, que ocupa $70 \%$ do Bioma Cerrado, tem a paisagem composta por um estrato herbáceo dominado principalmente por gramíneas, e estrato de árvores e arbustos tortuosos, com ramificações irregulares e retorcidas, variando em cobertura de 10 a $60 \%$ (EITEN, 1994).

Os dados sobre o hábito de crescimento corroboram com Neres e Conceição (2010), em que os dados permitem inferir que nas parcelas amostrados há uma grande variedade de espécies que vai desde arbusto, subarbusto até árvores, tendo, portanto, uma vegetação com indivíduos de pequeno, médio e grande porte, que contribuem de forma significante para a dinâmica da vegetação.

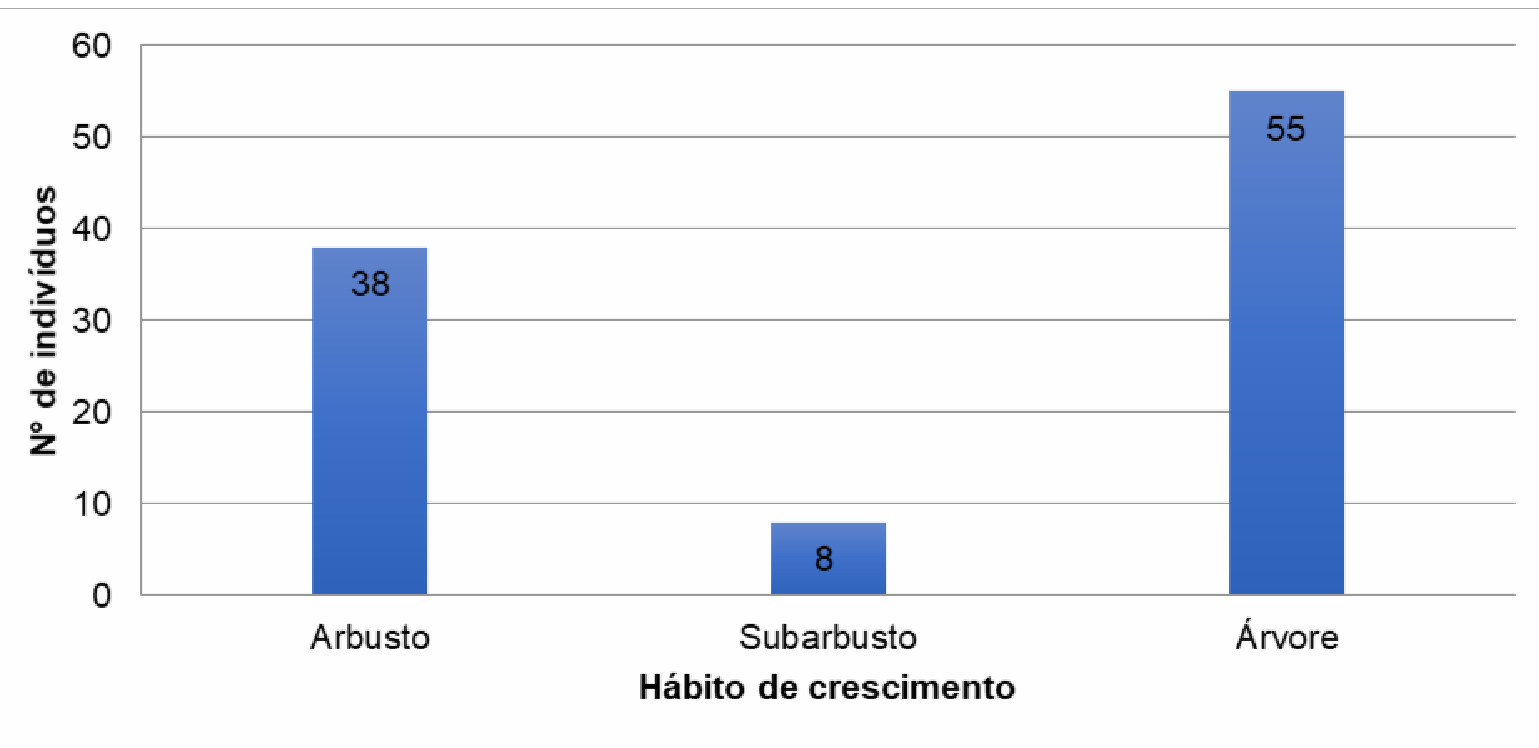

FIGURA 2. Distribuição percentual quanto ao hábito de crescimento da vegetação estudada na Área de Proteção Ambiental do Buriti do Meio, Caxias/MA.

Tratando-se dos dados da estrutura vegetacional relacionado as espécies, os mesmos estão apresentados na Tabela 1. as variáveis quanto ao número de indivíduos por espécie, Pseudobombax marginatum apresentou os maiores valores, com 20 indivíduos do total inventariado, maiores valores de Densidade Absoluta e Densidade Relativa, com 285,714 indivíduos por hectare e densidade relativa de $19,80 \%$, com uma área basal equivalente à 0,519 hectare respectivamente.

O gênero Pseudobombax tem distribuição Neotropical (ROBYNS, 1963), principalmente em áreas sob clima estacional no Cerrado e Caatinga e na região do 
semiárido nordestino, o gênero é o mais representativo da subfamília em número de espécies (CARVALHO SOBRINHO ; QUEIROZ, 2011). Pseudobombax marginatum possui biologia reprodutiva bem diversa o que garante a formação de várias populações e distribuição ampla nas áreas de ocorrência (PEQUENO et al., 2016).

TABELA 1. Distribuição dos dados da estrutura vegetacional relacionada as espécies da Área de Proteção Ambiental Municipal do Buriti do Meio.

\begin{tabular}{|c|c|c|c|c|c|c|c|}
\hline $\mathbf{N}^{\circ}$ & ESPÉCIES & $\mathrm{N}_{\mathrm{E}}$ & DA & DR & $\begin{array}{l}\text { Média } \\
\text { DNS }\end{array}$ & $\begin{array}{l}\text { Max } \\
\text { DNS }\end{array}$ & $\begin{array}{l}\text { Min } \\
\text { DNS }\end{array}$ \\
\hline 1. & Myrcia tomentosa & 1 & 14,286 & 0,99 & 10,83 & 10,83 & 10,83 \\
\hline 2. & Anacardium occidentale & 2 & 28,571 & 1,98 & 8,60 & 8,60 & 8,60 \\
\hline 3. & Diospyros hispida & 1 & 14,286 & 0,99 & 19,10 & 19,10 & 19,10 \\
\hline 4. & Inga laurina & 3 & 42,857 & 2,97 & 20,49 & 44,58 & 8,28 \\
\hline 5. & Parkia platycephala & 13 & 185,714 & 12,87 & 18,10 & 31,84 & 5,41 \\
\hline 6. & Himatanthus obovatus & 3 & 42,857 & 2,97 & 12,21 & 15,92 & 6,37 \\
\hline 7. & Qualea parviflora & 1 & 14,286 & 0,99 & 5,73 & 5,73 & 5,73 \\
\hline 8. & Tachigali glauca & 2 & 28,571 & 1,98 & 21,65 & 22,29 & 21,01 \\
\hline 9. & Combretum leprosum & 1 & 14,286 & 0,99 & 22,29 & 22,29 & 22,29 \\
\hline 10. & Curatella americana & 1 & 14,286 & 9 & 10,82 & 10,82 & 10,82 \\
\hline 11. & Caryocar brasiliense & 4 & 57,143 & 3,96 & 18,19 & 22,05 & 9,55 \\
\hline 12. & Terminalia argentea & 5 & 71,429 & 4,95 & 9,61 & 17,83 & 5,09 \\
\hline 13. & Salvertia convallariodora & 1 & 14,286 & 0,99 & 9,55 & 9,55 & 9,55 \\
\hline 14. & Cordiera sessilis & 1 & 14,286 & 0,99 & 9,55 & 9,55 & 9,55 \\
\hline 15. & Dimorphandra gardneriana & 1 & 14,286 & 9 & 25,47 & 25,47 & 25,47 \\
\hline 16. & Leptolobium dasycarpum & 1 & 14,286 & 0,99 & 16,56 & 16,56 & 16,56 \\
\hline 17. & Himatanthus drasticus & 6 & 85,714 & 5,94 & 14,65 & 19,10 & 7,32 \\
\hline 18. & Solanum lycocarpum & 2 & 28,571 & 1,98 & 10,98 & 11,46 & 10,50 \\
\hline 19. & Eugenia uniflora & 10 & 142,857 & 9,90 & 7,10 & 10,82 & 3,82 \\
\hline 20. & Plathymenia reticulata & 1 & 14,286 & 0,99 & 19,10 & 19,10 & 19,10 \\
\hline 21. & Casearia sylvestris & 4 & 57,143 & 3,96 & 7,00 & 7,96 & 5,73 \\
\hline 22. & Pterodon emarginatus & 4 & 57,143 & 3,96 & 8,59 & 11,46 & 5,73 \\
\hline 23. & Senegalia polyphylla & 1 & 86 & 0,99 & 22,29 & 22,29 & 22,29 \\
\hline 24. & Hymenaea stigonocarpa & 3 & 42,857 & 2,97 & 11,67 & 15,92 & 8,91 \\
\hline 25. & Pseudobombax marginatun & 20 & 285,714 & 19,80 & 12,61 & 63,69 & 3,50 \\
\hline 26. & Ouratea hexasperma & 1 & 14,286 & 0,99 & 61,14 & 61,14 & 61,14 \\
\hline 27. & Platonia insignis & 1 & 14,286 & 0,99 & 26,75 & 26,75 & 26,75 \\
\hline 28. & Terminalia fagifolia & 4 & 57,143 & 3,96 & 40,12 & 46,17 & 30,89 \\
\hline 29. & Vatairea macrocarpa & 1 & 14,286 & 0,99 & 5,73 & 5,73 & 5,73 \\
\hline 30. & Sterculia striata & 1 & 14,286 & 0,99 & 24,52 & 24,52 & 24,52 \\
\hline 31. & Xylopia aromática & 1 & 14,286 & 0,99 & 35,03 & 35,03 & 35,03 \\
\hline
\end{tabular}

Legenda: $\mathrm{N}_{\mathrm{E}}$ - Número de indivíduos por espécie; DA - Densidade absoluta por espécie; DR - Densidade relativa por espécie; Média DNS - Média do diâmetro à nível do solo; Max DNS -Diâmetro à nível do solo valor Máximo; Min DNS - Diâmetro ao nível do solo valor Mínimo.

Os menores valores de Densidade Absoluta e Relativa foram amostrados em diferentes espécies, que apresentaram apenas um único indivíduo no inventário, com um valor de 14,286 indivíduos por hectare para densidade absoluta e 0,99\% 
para densidade relativa. Espécie rara é aquela que ocorre na área com apenas um único indivíduo, possuindo valores baixos de densidade: Myrcia tomentosa, Diospyros hispida, Qualea parviflora, Combretum leprosum, Curatella americana, Salvertia convallariodora, Cordiera sessilis, Dimorphandra gardneriana, Leptolobium dasycarpum, Plathymenia reticulata, Senegalia polyphylla, Ouratea hexasperma, Platonia insignis, Vatairea macrocarpa, Sterculia striata e Xylopia aromática.

As espécies que apresentaram maior e menor média do DNS foram Ouratea hexasperma com 61,14 cm, Qualea parviflora e Vatairea macrocarpa com 5,73 cm, respectivamente. $O$ tamanho do indivíduo determina não somente as taxas de crescimento, como também a sobrevivência e reprodução de uma planta, tratandose de crescimento secundário o diâmetro é um valor de alta significância para os organismos vegetais, principalmente plantas do cerrado que podem utilizar o crescimento secundário para proteção de vasos pelos ataques comuns do fogo (CRISTIANINI et al., 2004).

Relacionando o número de indivíduos por parcela, obteve-se uma proporção variada, a parcela sete amostrou o maior número de indivíduos, com 20 espécimes e a parcela dois, com apenas sete indivíduos (Fig. 3). Na margem direita (quatro parcelas) obteve-se um total de 56 indivíduos e na margem esquerda (três parcelas) apenas 45 indivíduos. Os dados encontrados mostram-se com um número baixo de indivíduos, principalmente nas parcelas dois e cinco e ressalta-se que muito da área é antropizada, o que interfere na cobertura vegetacional local. A cobertura original do cerrado brasileiro já foi reduzida em mais de 37\% (FELFILI et al., 2002), comprometendo muito a biodiversidade e prejudicando os trabalhos de caracterização vegetacional.

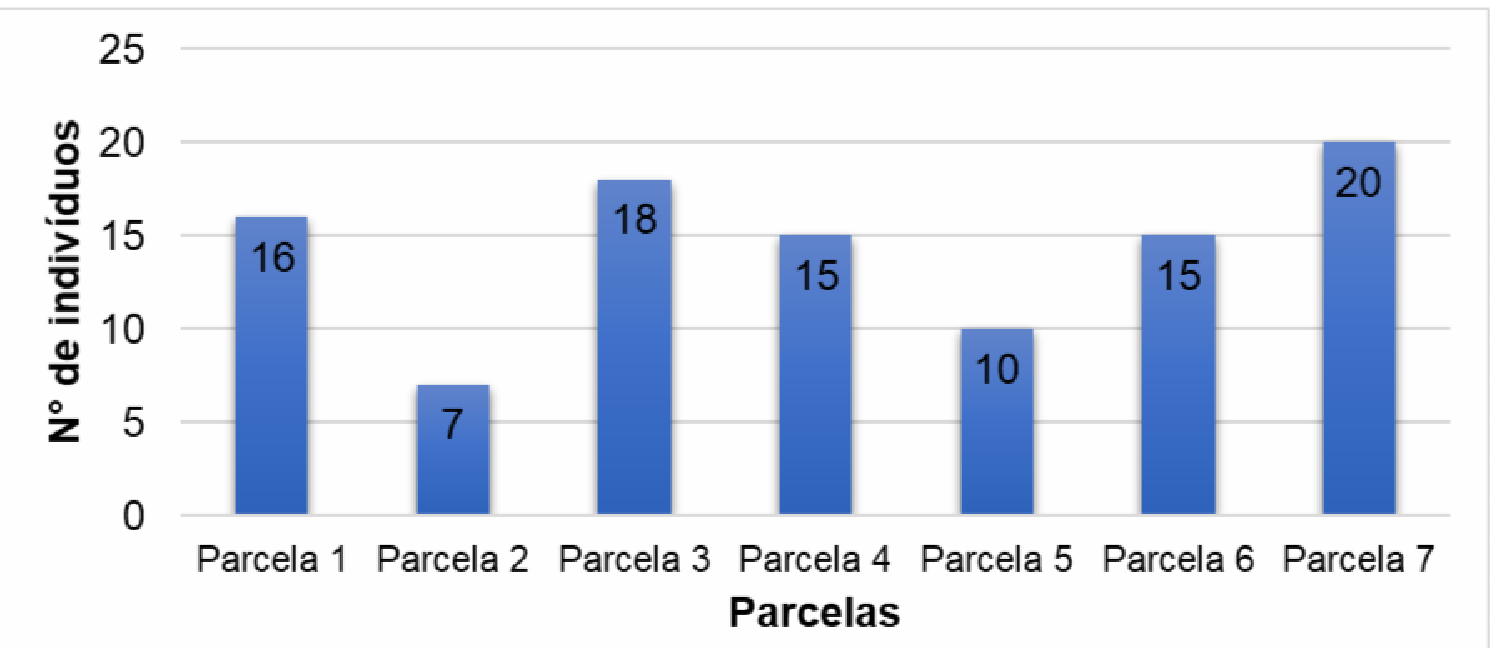

FIGURA 3. Distribuição do número de indivíduos coletados por parcela na Área de Proteção Ambiental Municipal do Buriti do Meio.

O fragmento em estudo tem boa parte da área desmatada, como fruto da ocupação de moradores e o estabelecimento de culturas agrícolas, bem como a retirada de madeira e introdução de gado para pastejo. Segundo Sano et al. (2007) aproximadamente $47 \%$ das áreas naturais do Cerrado já foram modificadas para atividades de uso antrópico - cultura agrícola, pastagens nativas e cultivadas, reflorestamento, área urbana e mineração.

Quanto aos dados da estrutura vegetacional relacionado as parcelas, os 
mesmos estão apresentados na Tabela 2, denotando dados que contribuem de forma significante para a compreensão da estrutura arbóreo-arbustiva da APA. Observa-se nos valores indicados que a maior média do diâmetro a nível do solo (DNS) ocorreu na Parcela seis, com 23,61 cm, nesta parcela ocorreram vários representantes de Pseudobombax marginatum acarretando valores altos. Esses dados correspondem a uma vegetação arbórea de plantas altas, com altura de caules altos e com uma ramificação simpodial alongada. Os dados podem pressupor que a grande quantidade de árvores podem ser um indicativo de baixa taxa de mortalidade ou de queda relativamente rápida das árvores e arbustos mortos.

TABELA 2. Distribuição dos dados da estrutura vegetacional relacionada as parcelas da Área de Proteção Ambiental Municipal do Buriti do Meio.

\begin{tabular}{cccccc}
\hline Parcelas & Ni & AB & $\begin{array}{c}\text { Média } \\
\text { DNS }\end{array}$ & Max DNS & Min DNS \\
\hline $\mathbf{1}$ & 16 & 0,336 & 14,95 & 23,57 & 5,41 \\
\hline $\mathbf{2}$ & 7 & 0,126 & 13,96 & 25,47 & 7,32 \\
\hline $\mathbf{3}$ & 18 & 0,256 & 11,94 & 23,56 & 4,77 \\
\hline $\mathbf{4}$ & 15 & 0,293 & 14,01 & 31,84 & 3,82 \\
\hline $\mathbf{5}$ & 10 & 0,132 & 11,91 & 19,10 & 5,73 \\
\hline $\mathbf{6}$ & 15 & 1,099 & 23,61 & 63,69 & 5,73 \\
\hline $\mathbf{7}$ & 20 & 0,613 & 14,74 & 44,58 & 3,50 \\
\hline
\end{tabular}

Legenda: $\mathrm{Ni}$ - Número de indivíduos por parcela; $\mathrm{AB}$ - Área basal; DNS - Diâmetro à nível do solo; Max DNS - Diâmetro à nível do solo valor Máximo; Min DNS - Diâmetro à nível do solo valor Mínimo.

Considerando a menor média do DNS ocorreu na parcela cinco com 11,91 $\mathrm{cm}$, as plantas na maioria eram do tipo arbusto e subarbusto. Os arbustos e subarbustos apresentam córtex espesso, típico de plantas do Cerrado devido a adaptação dos fatores abióticos e também do típico fogo de cerrado (MAZZONIVIVEIROS ; COSTA, 2003).

Contribuindo de forma notória para o estudo, a área basal apresentou o maior índice na parcela seis com o valor de $1,099 \mathrm{~m}^{2}$ demonstrando assim, grande densidade vegetacional, que por sua vez está relacionada à presença e distribuição dos indivíduos. Gorenstein (2002) afirma que métodos construídos para estimar volume e área basal de povoamentos florestais homogêneos são importantes, e que também pode ser empregado para estudos ecológicos, porém a eficácia estará atrelada ao comportamento à área basal da comunidade, que constitui apenas um dos parâmetros considerados relevantes na amostragem.

A análise de Diversidade vegetacional (Tabela 3), através dos índices escolhidos representa que os dados obtidos corroboram, com os trabalhos de Conceição e Castro (2009); Neres e Conceição (2010) e Soares et al. (2010) em riqueza local, a relação de espécies abundantes e raras, dominância de espécies, uniformidade da distribuição das espécies na amostra e a composição florística da vegetação analisada, apresentando um padrão para estrato arbóreo arbustivo do Cerrado no Leste maranhense. 
TABELA 3. Análises da Diversidade vegetacional obtidas pelos índices ecológicos investigados na Área de Proteção Ambiental Municipal do Buriti do Meio.

\begin{tabular}{cccccccc}
\hline Parcelas & $\mathbf{N i}$ & $\mathbf{S}$ & $\mathbf{I n}(\mathbf{S})$ & $\mathbf{H}^{\prime}$ & $\mathbf{C}$ & $\mathbf{J}$ & $\mathbf{Q M}$ \\
\hline $\mathbf{1}$ & 16 & 11 & 2,398 & 2,27 & 0,94 & 0,95 & $1: 1,45$ \\
\hline $\mathbf{2}$ & 7 & 7 & 1,946 & 1,95 & 1,00 & 1,00 & $1: 1,00$ \\
\hline $\mathbf{3}$ & 18 & 6 & 1,792 & 1,69 & 0,85 & 0,94 & $1: 3,00$ \\
\hline $\mathbf{4}$ & 15 & 8 & 2,079 & 1,90 & 0,89 & 0,91 & $1: 1,88$ \\
\hline $\mathbf{5}$ & 10 & 6 & 1,792 & 1,70 & 0,89 & 0,95 & $1: 1,67$ \\
\hline $\mathbf{6}$ & 15 & 8 & 2,079 & 1,71 & 0,79 & 0,82 & $1: 1,88$ \\
\hline $\mathbf{7}$ & 20 & $\mathbf{4}$ & 1,386 & 1,03 & 0,56 & 0,74 & $1: 5,00$ \\
\hline
\end{tabular}

Legenda: $\mathrm{Ni}$ - Número de indivíduos por parcela; S - Número de espécies; $\ln (\mathrm{S})$ Diversidade Máxima; H' - Índices de diversidade de Shannon-Weaver; C - Índice de dominância de Simpson; J - Equitabilidade de Pielou; QM - Coeficiente de Mistura de Jentsch.

O maior índice de diversidade máxima ocorreu na parcela um com 2,398 com 11 espécies, com maior índice de Shannon-Weaver, atingindo o valor de 2,27 nats/ind; enquanto que a parcela sete apresentou o menor índice, com 1,03 nats/ind com quatro espécies inventariadas. Observa-se que quanto maior a diversidades de espécies encontradas nas parcelas, menor será o índice de Pielou, pois há uma interferência no equilíbrio de espécies.

Com relação ainda aos dados do índice de Pielou e de Simpson, a maior uniformidade e dominância ocorreu na parcela dois, a mesma amostrou sete indivíduos, com sete espécies, isso quer dizer que todas as espécies desta parcela são igualmente abundantes quando comparadas as outras parcelas. Nas demais parcelas, o índice de Pielou e Simpson, a equitabilidade e dominância baixa, reforça ainda mais que a área passa por forte pressão antrópica e como consequência o número de espécies vegetais nativas vem desaparecendo, dando assim espaço a ocupação de espécies invasoras. Outra hipótese seria o fato do cerrado apresentar grande variedade de espécies, que ao longo da APA foram distribuídas de forma não uniforme e com pouca dominância. Ridley (2006) e Rizzini (1997) afirmam que a distribuição das espécies num ambiente reflete o nível de adaptabilidade frente às diversas pressões seletivas, uma vez que devem existir condições essenciais à sobrevivência para que ocorra a ocupação e a colonização de determinado local.

$\mathrm{Na}$ área de estudo foi analisado o Coeficiente de Mistura de Jentsch, observou-se que a parcela sete apresentou maior proporção média no número de árvores de cada espécie, com uma proporção de 1:5,00 ou seja uma árvore a cada cinco povoamentos estimados. Isso deve-se ao grande número de Pseudobombax marginatum dentro da parcela. Dessa forma, possuir um fator para medir a intensidade de mistura das espécies e os possíveis problemas de manejo, dada as condições de variabilidade é de suma importância principalmente tratando-se do Cerrado. Camelo Júnior et al. (2017) em levantamento na APA de estudo apresentaram 89 espécies, distribuídos em 78 gêneros e 32 famílias botânicas, verificando o quão variável e diverso é a composição florística da área, corroborando com a composição vegetacional.

\section{CONCLUSÃO}

Para entendimento da composição arbóreo arbustiva da área de estudo foram inventariados 101 espécimes, distribuídos em 31 gêneros e 31 espécies, que se 
agruparam nos padrões metodológicos das sete parcelas inventariadas. O principal hábito de vida das espécies é do tipo árvore, seguida de arbusto e subarbusto, verificando um forte componente arbóreo-arbustivo na vegetação.

Nas parcelas investigadas, a parcela sete amostrou o maior número de indivíduos com 20 espécimes e a parcela dois teve o menor índice com apenas sete indivíduos. Tratando das análises estruturais da vegetação por espécie, as populações de Pseudobombax marginatum foram determinantes para indicar os maiores valores de densidade absoluta e relativa, e que os menores valores foram representados por espécies com apenas um indivíduo dentro da parcela, e o Diâmetro ao Nível do Solo foi variável, dependendo do crescimento secundário da espécie.

As análises de diversidade da vegetação através dos índices calculados corroboraram com vários trabalhos em riqueza local, a relação de espécies abundantes e raras, dominância de espécies, uniformidade da distribuição das espécies na amostra e a composição florística da vegetação analisada, apresentando um padrão para estrato arbóreo arbustivo do Cerrado no Leste maranhense. Assim percebe-se que a vegetação é bem diversa, mas que passa por constantes pressões antrópicas, sujeita à drásticas mudanças da estrutura arbóreoarbustiva.

\section{REFERÊNCIAS}

CAMELO JÚNIOR, A. E.; SILVA, G. S.; CONCEIÇÃO, G. M. Florística de um Fragmento Vegetacional da Área de Proteção Ambiental do Buriti do Meio, Caxias, Maranhão. Agrarian Academy. v. 4, n. 7; p. 268-279, 2017. DOI: 10.18677/Agrarian_Academy_2017a26.

CARVALHO-SOBRINHO, J. G.; QUEIROZ, L. P. Morphological cladistic analysis of Pseudobombax Dugand (Malvaceae, Bombacoideae) and allied genera. Revista Brasileira de Botânica. v. 34, p. 197-209, 2011. http://dx.doi.org/10.1590/S010084042011000200007

CONCEIÇÃO, G. M.; CASTRO, A. A. J. F. Fitossociologia de uma área de cerrado marginal, Parque Estadual do Mirador, Mirador, Maranhão. Scientia Plena. v. 5, n. 10, p. 16, 2009. https://scientiaplena.org.br/sp/article/viewFile/643/305

CRISTIANINI, A. V.; VIRILLO, C. B.; COLPAS, F. T.; COSTA, R. C. Relações entre Diâmetro e altura e Diâmetro e espessura do Córtex em espécies de Cerrado do Município de Itirapina, SP. Unicamp, 2004. Disponível em: https://www2.ib.unicamp.br/profs/fsantos/ecocampo/ne211/2004/relat1b.pdf Acesso em: 28/11/2017.

EITEN, G. Vegetação do Cerrado. In: PINTO, M. N. Cerrado: caracterização, ocupação e perspectivas. Brasília, Ed. UnB/SEMATEC. p. 17-73, 1994.

ESTADO DO MARANHÃO. Plano de Ação para prevenção e Controle do Desmatamento e das Queimadas no Estado do Maranhão - Decreto no 27.317. Governo do Estado do Maranhão. Secretaria de Estado do Meio Ambiente e Recursos Naturais. São Luís, Maranhão, p. 110, 2011. http://www.fundoamazonia.gov.br/FundoAmazonia/export/sites/default/site_pt/Galeri as/Arquivos/Publicacoes/Plano_Estadual_do_Maranhxo.pdf

FELFILI, J. M.; NOGUEIRA, P. E.; SILVA JÚNIOR, M. C.; MARIMON, B. S.; AGRARIAN ACADEMY, Centro Científico Conhecer - Goiânia, v.4, n.8; p.55 2017 
DELITTI, W. B. C. Composição florística e fitossociologia do cerrado sentido restrito no município de Água Boa, MT. Acta Botânica Brasílica. v. 16, n. 1, p. 103-112, 2002. http://dx.doi.org/10.1590/S0102-33062002000100012.

FERREIRA, K. B. Estudo fitossociológico em uma área de cerrado marginal no município de Afonso Cunha - MA. Monografia de Graduação. Universidade Federal do Maranhão, São Luís. p. 69, 1997.

FIASCHI, P.; PIRANI, J. R. Review of plant biogeographic studies in Brazil. Journal of Systematic and Evolution. v. 47, n. 5, p. 477-496, 2009. DOI: 10.1111 / j.17596831.2009.00046.x

FIDALGO, O.; BONONI, V. L. R. Técnicas de coleta, preservação e herborização de material botânico. Instituto de Botânica. São Paulo, p. 62, 1989.

GOMES, B. Z.; MARTINS, F. R.; TAMASHIRO, J. Y. Estrutura do cerradão e da transição entre cerradão e floresta paludícola num fragmento da International Paper do Brasil Ltda., em Brotas, SP. Revista Brasil. Bot. v. 27, n. 2, p. 249-262, 2004. http://dx.doi.org/10.1590/S0100-84042004000200005

GORENSTEIN, M. R. Métodos de amostragem no levantamento da comunidade arbórea em Floresta Estacional Semidecidual. Dissertação apresentada a Escola Superior de Agricultura "Luiz de Queiroz", Universidade de São Paulo. Piracicaba, São Paulo. p. 102, 2002.

IBGE. Censo. Instituto Brasileiro de Geografia e Estatística. 2010. Disponível em: http:<//www1.ibge.gov.br/cidadesat/topwindow.htm?1>. Acesso em: 20/11/2017.

IBGE. Instituto Brasileiro de Geografia e Estatística. Malha municipal do Estado do Maranhão Resolução de 02/10/2002. 2002.

MANZZONI-VIVEIROS, S. C.; COSTA, C. G. Periderme. In: APEZZATO-DAGLORIA, B.; CARMELLO-GUERREIRO, S. M. Anatomia Vegetal. Editora UFV, Viçosa. p. 237-263, 2003.

MARTINS, F. R. Para que serve a fitossociologia? In: JARDIM, M. A. G.; BASTOS, M. N. C.; SANTOS, J. U. M. Desafios da Botânica Brasileira no Novo Milênio: inventário, sistematização e conservação da diversidade vegetal. Belém: Museu Paraense Emílio Goeldi, EMBRAPA Amazônia Oriental. p. 252-254, 2003.

MONTES, M. L.; COSTA, R. C. R.; SILVA, G. B.; FONSECA, E. G.; ORLANDI, R. P.; LIMA, E. A.; FONSECA, A. L. B.; SOKOLONSKI, H. H. Zoneamento Geoambiental do Estado Do Maranhão - Diretrizes Gerais Para a Ordenação Territorial. Ministério de Planejamento, Orçamento e Coordenação. Fundação Instituto Brasileiro de Geografia e Estatística. Salvador. p. 44, 1997. https://biblioteca.ibge.gov.br/visualizacao/livros/liv95885.pdf

MYERS, N.; MITTERMEIER, R. A.; MITTERMEIER, C. G.; FONSECA, G. A. B.; KENT, J. Biodiversity hotspots for conservation priorities. Nature, v. 403, p. 853-858, 2000. Doi: 10.1038 / 35002501.

NERES, L. P.; CONCEIÇÃO, G. M. Florística e Fitossociologia da Área de Proteção 
Ambiental Municipal do Inhamum, Caxias, Maranhão, Brasil. Cadernos de

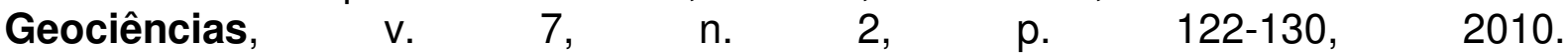
https://portalseer.ufba.br/index.php/cadgeoc/article/view/4531/3550.

PEQUENO, I. D.; ALMEIDA, N. M.; SIQUEIRA FILHO, J. A. Biologia reprodutiva e guilda de visitantes florais de Pseudobombax marginatum (Malvaceae). Rodriguésia. v. 67, n. 2, p. 395-404, 2016. http://dx.doi.org/10.1590/21757860201667211.

RATTER, J. A.; BRIDGEWATER, S.; RIBEIRO, J. F. Analysis of the floristic composition of the Brazilian cerrado vegetation iii: comparison of the woody vegetation of 376 areas. Edinburgh Journal of Botany. v. 60, p. 57-109, 2003. https://doi.org/10.1017/S0960428603000064

RIDLEY, M. Evolução. 3a ed. Porto Alegre, Artmed, p. 752, 2006.

RIZZINI, C. T. Tratado de Fitogeografia do Brasil. São Paulo, 2. ed.. Âmbito Cultural, p. 747, 1997.

ROBYNS, A. Essai de Monographie du genre Bombax L. s.l. (Bombacaceae). Bulletin du Jardin Botanique de l'État. v. 33, p. 1-315. 1963. http://www.jstor.org/stable/3667210

SALIS, S. M.; TAMASHIRO, J. Y.; JOLY, C. A. Florística e fitossociologia do estrato arbóreo de um remanescente de mata ciliar do rio Jacaré-Pepira, Brotas, SP. Revista Brasileira de Botânica. v. 17, p. 93-103, 1994. https://www.researchgate.net/publication/285076710_Floristica_e_fitossociologia_do estrato_arboreo_de_um_remanescente_de_mata_ciliar_do_rio_JacarePepira_Brotas_SP

SANO, E. E.; FERREIRA, L. G. Monitoramento semidetalhado (escala 1:250.000) de ocupação de solos do cerrado: considerações e proposta metodológica. Anais do XII Simpósio Brasileiro de Sensoreamento Remoto. Goiânia, INPE. p. 3309-3316, 2005.

SANO, E. E.; ROSA, R.; BRITO, J. L. S.; FERREIRA, L. G. Mapeamento semidetalhado do uso da terra do Bioma Cerrado. Pesquisa Agropecuária Brasileira. v. 43, n. 1, p.153-156, 2008. http://dx.doi.org/10.1590/S0100204X2008000100020.

SANO, E. E.; ROSA, R.; BRITO, J. L.; FERREIRA JR, L. G. Mapeamento de cobertura vegetal do bioma Cerrado: estratégias e resultados. Planaltina: Embrapa Cerrados, (Boletim de Pesquisa), p. 33, 2007.

SILVA-FILHO, J. F. Florística e fitossociologia da área de proteção ambiental municipal do Inhamum do município de Caxias e comparação com outras áreas do Estado do Maranhão, Brasil. Monografia (Graduação em Biologia) Universidade Estadual do Maranhão, Centro de Estudos Superiores de Caxias. p. 68, 2006.

SOARES, Z. T. Fitossociologia do Estrato Arbóreo em uma Área de Cerrado na Amazônia Oriental, Maranhão. Monografia de Graduação. Universidade Estadual 
do Maranhão, Centro de Estudos Superiores de Imperatriz, Imperatriz. p.187, 1996.

SOARES, Z. T.; COSTA, A. P. S.; SOARES, E. F.; CAVALCANTI, V. F. S. Levantamento Florístico e Fitossociológico em uma área de cerrado no Sudoeste do Maranhão. Iniciação Científica CESUMAR. v. 12, n. 2, p. 111-120. 2010.

STRASSBURG, B. B. N.; BROOKS, T.; FELTRAN-BARBIERI, R.; IRIBARREM, A.; CROUZEILLES, R.; LOYOLA, R.; LATAWIEC, A. E.; OLIVEIRA-FILHO, F. J. B.; SCARAMUZZA, C. A. M.; SCARANO, F. R.; SOARES-FILHO, B.; BALMFORD, A. Moment of truth for the Cerrado hotspot. Nature Ecology \& Evolution. v. 1, n. 0099, p. 1-3, 2017. Doi: 10.1038 / s41559-017-0099.

TEIXEIRA JUNIOR, G. M.; CONCEIÇÃO, G.M. Florística do estrato arbustivoarbóreo de uma área de cerrado marginal no município de Caxias, MA. In Congresso Nacional de Botânica, 52. Resumos. João Pessoa: UFPB, p. 202, 2001. 